\title{
MODEL PENDIDIKAN KARAKTER DI ISLAMIC FULL DAY SCHOOL (Studi Deskriptif pada SD Cendekia Leadership School, Bandung)
}

\author{
Oci Melisa Depiyanti ${ }^{\star}$ \\ Program Studi Ilmu Pendidikan Agama Islam, \\ Fakultas Ilmu Pengetahuan Sosial, Universitas Pendidikan Indonesia \\ *E-mail:oci.melisa@gmail.com
}

\begin{abstract}
ABSTRAK
Penelitian ini berawal dari sebuah teori bahwa manusia dapat di didik dan perlu untuk didik. Manusia memeliki potensi-potensi yang harus dibimbing. Dunia pendidikan selama ini diharapkan menjadi tumpuan untuk menfasilitasi hal tersebut, pendidikan selama ini juga diharapkan mampu menjadi akhir penjaga nilai-nilai kejujuran dan moral bangsa. Namun yang terjadi justeru sebaliknya, banyak faktor yang menyebabkan gagalnya pendidikan yakni faktor lingkungan, kurangnya perhatian orang tua, model pendidikan, metode yang kurang tepat, materi yang tidak sesuai, kepribadian guru dll. Sebagai upaya untuk menanggulangi permasalahan di atas, pemerintah mulai menggalakkan pendidikan karakter. Peneliti beranggapan bahwa penyelesaian berbagai masalah di atas dapat di awali dengan pembenahan model pendidikan di sekolah dasar. Dengan berdasarkan dua ungkapan yang menyatakan bahwa 'substansi materi itu lebih penting daripada metode', dan ungkapan yang kedua menyatakan sebaliknya bahwa 'metode lebih penting daripada substansi materi'. Dari kedua ungkapan tersebut peneliti menyimpulkan bahwa substansi materi dan metode sama pentingnya dan keduanya terangkum dalam sebuah model pendidikan. Peneliti memilih model pendidikan karakter di SD Islamic full day school, karena pendidikan karakter harus dibangun dari dasar. SD Cendekia Leadership School menjadi pilih n peneliti karena sekolah tersebut menerapkan kurikulum Leadership yang diintegrasikan dengan nilai- nilai agama Islam yang mengembangkan sevent life skills, dan sistem $4 \mathrm{H}$; hands, head, health dan heart. Penelitian ini menggunakan metode deskriptif dengan pendekatan kualitatif. Sumber data diperoleh dari narasumber, peristiwa, lokasi dan dokumentasi. Teknik pengumpulan data dilakukan dengan cara wawancara, observasi partisipatif dan kajian dokumentasi. Hasil penelitian berupa gambaran konstruk model pendidikan yang dilaksanakan di SD Cendekia Leadershi School. Melalui sistem $4 \mathrm{H}$ dikembangkan 35 ranah sebagai materi pendidikan karakter dengan indikator yang jelas pada setiap tahap perkembangan anak. Metode pembiasaan dan pengalaman secara langsung menjadi metode utama dalam pelaksanaan pendidikan karakter di sekolah tersebut.
\end{abstract}

Kata Kunci : Model Pendidikan Karakter; Pendidikan Karakter; Islamic Full Day School; SD Cendekia Leadership School. 


\section{PENDAHULUAN}

Manusia tidak dapat lepas dari pendidikan, karena pada hakikatnya manusia itu mempunyai potensi-potensi yang memungkinkannya untuk dididik dan mempunyai potensi untuk dapat dididik. Terkait dengan hal tersebut Drijarkara 9dalam Rasyidin, 2008, hal. 17) menyatakan bahwa:

Manusia mempunyai atau berupa dinamika (manusia sebagai dinamika), artinya manusia tidak pernah berhenti, selalu dalam keaktifan, baik dalam aspek fisiologik maupun spritualnya. Dinamika mempunyai arah horisontal (ke arah sesama dan dunia) maupun arah transendental (ke arah Yang Mutlak). Adapun dinamika itu adalah untuk penyempurnaan diri baik dalam hubungannya dengan sesama, dunia dan Tuhan.

Di samping itu, eksistensi manusia adalah untuk menjadi manusia, hal tersebut menegaskan bahwa manusia pada dasarnya ingin mengeksistensikan dirinya sebagai manusia yang ideal.

Manusia yang ideal adalah manusia yang mampu mewujudkan berbagai potensinya secara optimal, sehingga beriman dan bertaqwa kepada Tuhan YME, beraklak mulia, sehat, cerdas, berperasaan, berkemauan, dan mampu berkarya; mampu memenuhi berbagai kebutuhannya secara wajar, mampu mengendalikan hawa nafsunya; berkepribadian, bermasyarakat dan berbudaya (Rasyidin, 2008, hal. 18).

Namun demikian yang terjadi justru sebaliknya, dewasa ini bangsa Indonesia sedang mengalami krisis moral, hal ini nampak dari berbagai peristiwa yang akhir- akhir ini terjadi, korupsi semakin merajalela di tanah air ini, hal ini dapat kita saksikan setiap hari di pelbagai media masa di tanah air semakin banyak kasus korupsi yang terungkap, keadilan dalam penegakkan hukum pun sudah menjadi barang langka karena kejujuran sudah menjadi suatu yang hampir punah di tanah air tercinta ini, para penegak hukum saling menyalahkan dan mengkambing hitamkan sehingga tidak dapat membedakan lagi mana yang putih dan hitam semuanya terlihat abu-abu, ditambah lagi kita harus menyaksikan pertikaian antar institusi penegak hukum. Banyak yang mengidap penyakit akut "split personality" (kepribadian yang terpecah) di mana teori dan praktiknya berbeda. Hal ini telah diungkapkan dalam QS. Al-Shaf (61): 2-3.
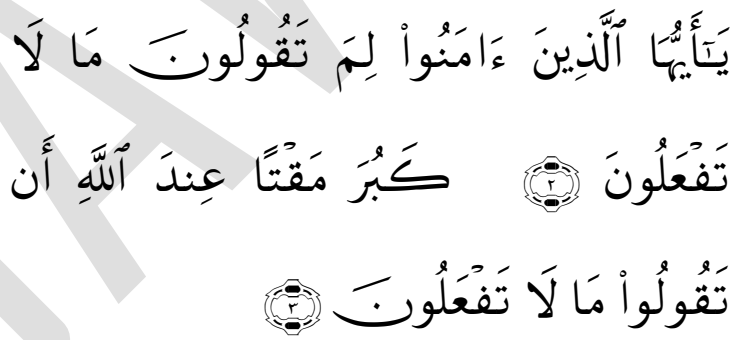

Artinya: "Wahai orang-orang yang beriman, kenapakah kamu mengatakan sesuatu yang tidak kamu kerjakan? Amat besar kebencian di sisi Allah bahwa kamu mengatakan apaapa yang tidak kamu kerjakan"

Banyak faktor yang menjadi penyebab ketidakberhasilan pendidikan, diantaranya; kebijakan pemerintah mengenai sistem pendidikan, kurikulum pendidikan, anggaran pendidikan, keperibadian guru, metode pengajaran yang tidak tepat, peran orang tua yang kurang, lingkungan belajar yang tidak kondusif, dan model pembelajaran yang tidak tepat. 
Sebagai solusi pemerintah menganjurkan agar sekolah-sekolah menggunakan model pendidikan karakter, model pendidikan konvensional atau model pendidikan kinestetik dipandang sudah tidak cukup mampu untuk menghalau arus deras dampak globalisasi.

Oleh karena itu, dalam penelitian ini penulis hendak menggambarkan model pendidikan karakter yang dikembangkan oleh sekolah yang berbasis full day school. Full day school sebagai sekolah yang bersifat hommy. SD Cendekia Leadership School adalah salah satu sekolah dengan program full day school, sekolah yang mempunyai konsep dasar Leadership yang diintegrasikan dengan pendidikan Agama Islam yang menjadi tumpuan dasar untuk mewujudkan visi dan misi sekolah.

Peneliti merumuskan pertanyaan umum yakni bagaimana model pendidikan karakter di SD Cendekia Leadership School?

Berdasarkan rumusan pertanyaan umum di atas, maka peneliti merinci pertanyaan penelitian ini dalam beberapa poin, sebagai berikut:

pendidikan karakter di SD

Cendekia Leadership School?

2. Bagaimana pelaksanaan pendidikan karakter di SD Cendekia Leadership School?

3. Bagaimana evaluasi pendidikan karakter di SD Cendekia Leadership School?

4. Apa saja faktor penghambat dan penunjang pendidikan karakter di SD Cendekia Leadership School?

5. Bagaimana konstruk model pendidikan karakter di SD Cendekia Leadership School?

\section{KAJIAN PUSTAKA}

Suhartono (2009, hal. 77) menyatakan bahwa istilah pendidikan berasal dari bahasa Inggris yang lain, yakni:

Education, berakar dari bahasa latin educare, yang dapat diartikan bimbingan berkelanjutan (to lead forth)". Jika diperluas, arti etimologis itu mencerminkan keberadaan pendidikan yang berlangsung dari generasi ke generasi sepanjang eksistensi kehidupan manusia.

Sedangkan Muhadjir (dalam Suwarno, 2009, hal. 9) menyatakan:

Istilah pendidikan berasal dari bahasa Yunani, Paedagogy, yang mengandung makna seorang anak yang pergi dan pulang sekolah diantar seorang pelayan. Sedangkan pelayan yang menjemput dinamakan paedagogos. Dalam bahasa Romawi, pendidikan disitilahkan dengan educate yang berarti mengeluarkan sesuatu yang berada di dalam. Sedangkan dalam bahasa inggris, pendidikan diistilahkan to educate yang bearti memperbaiki moral dan melatih intelektual.

Secara harfiah karakter artinya 'kualitas mental atau moral, kekuatan moral, nama atau reputasi'. Menurut Kamus Lengkap Bahasa Indonesia, "karakter adalah sifat-sifat kejiwaan, akhlak atau budi pekerti yang membedakan seseorang dengan yang lain; tabiat; watak" (2008: 623).

Aziz (2011: 121) menyimpulkan bahwa:

Karakter adalah kualitas atau kekuatan mental dan moral, akhlak atau budi pekerti individu yang merupakan kepribadian khusus yang membedakan dengan individu lain. 
Lebih lanjut Aziz mengungkapkan bahwa karakter pendidikan adalah kualitas mental dan kekuatan moral, akhlak atau budi pekerti dari nilai-nilai dan keyakinan yang ditanamkan dalam proses pendidikan yang merupakan kepribadian khusus yang harus melekat pada peserta didik.

Sedangkan Russel Williams sebagaimana yang dikutip oleh Megawangi dalam tulisannya Mampukan Kita Memperbaiki Kondisi Moral Bangsa? (Q-nees dan Hambali, 2009: 99) mengilustrasikan bahwa karakter adalah ibarat otot, dimana otot-otot karakter akan menjadi lembek apabila tidak pernah dilatih, dan akan kuat dan kokoh kalau sering dipakai.

Menurut Megawangi (2004, hal. 95), pendidikan karakter adalah :

Sebuah usaha untuk mendidik anakanak agar dapat mengambil keputusan dengan bijak dan memperatekkannya dalam kehidupan sehari-hari, sehingga mereka dapat memberikan kontribusi yang positif kepada lingkungannya.

Berdasarkan pada pedoman pelaksanaan pendidikan karakter yang bersumber dari Kementerian Pendidikan Nasional Badan Penelitian Dan Pengembangan Pusat Kurikulum Dan Perbukuan (2011) Pendidikan karakter bertujuan mengembangkan nilai-nilai yang membentuk karakter bangsa yaitu Pancasila, meliputi :

1. Mengembangkan potensi peserta didik agar menjadi manusia berhati baik, berpikiran baik, dan berprilaku baik;

2. Membangun bangsa yang berkarakter Pancasila;

3. Mengembangkan potensi warga negara agar memiliki sikap percaya diri, bangga pada bangsa dan negaranya serta mencintai umat manusia.

Pendidikan karakter meliputi dua aspek yang dimiliki manusia, yaitu aspek ke dalam dan aspek keluar. Aspek ke dalam atau aspek potensi meliputi aspek kognitif (olah pikir), afektif (olah hati), dan psikomotor (olah raga). Masingmasing aspek memiliki ruang yang berisi nilai-nilai pendidikan karakter. Penjelasan ruang lingkup pendidikan karakter terdapat pada bagan di bawah ini:

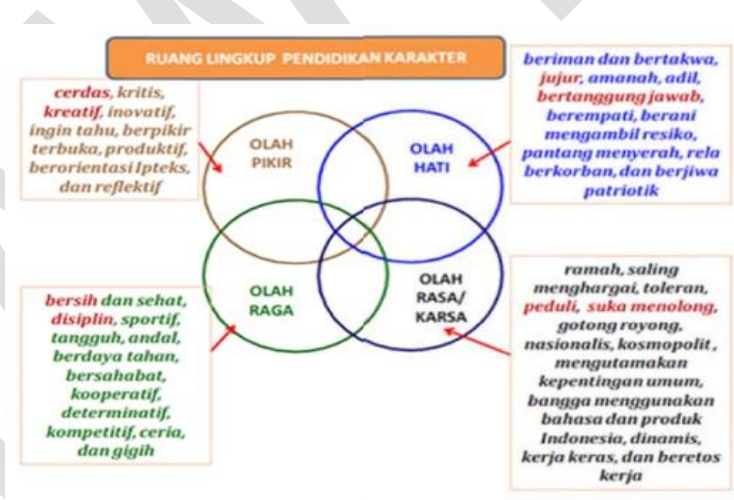

Gambar 1. Bagan Konfigurasi Pendidikan Karakter

Dalam pendidikan karakter telah teridentifikasi 18 nilai yang bersumber dari agama, Pancasila, budaya, dan tujuan pendidikan nasional, yaitu: (1) Religius, (2) Jujur, (3) Toleransi, (4) Disiplin, (5) Kerja keras, (6) Kreatif, (7) Mandiri, (8) Demokratis, (9) Rasa Ingin Tahu, (10) Semangat Kebangsaan, (11) Cinta Tanah Air, (12) Menghargai Prestasi, (13) Bersahabat/Komunikatif, (14) Cinta Damai, (15) Gemar Membaca, (16) Peduli Lingkungan, (17) Peduli Sosial, (18) Tanggung Jawab (Pusat kurikulum: Pengembangan dan Pendidikan Budaya; Karakter Bangsa: Pedoman Sekolah, 2009: 9-10). 
Aqib dan Sujak (2011: 11) menuliskan prinsip pendidikan karakter pada sebuah sekolah, bahwa pendidikan karakter harus didasarkan pada prinsip prinsip sebagai berikut:

1. Mempromosikan nilai-nilai dasar etika sebagai basis karakter.

2. Mengidentifikasi karakter secara komprehensif supaya mencakup pemikiran, perasaan, dan perilaku.

3. Menggunakan pendekatan yang tajam, proaktif dan efektif untuk membangun karakter.

4. Menciptakan komunitas sekolah yang memiliki kepedulian.

5. Memberi kesempatan kepada peserta didik untuk menunjukkan perilaku yang baik.

6. Memiliki cakupan terhadap kurikulum yang bermakna dan menantang yang menghargai semua peserta didik, membangun karakter mereka, dan membantu mereka untuk sukses.

7. Mengusahakan tumbuhnya motivasi diri pada para peserta didik.

8. Memfungsikan seluruh staf sekolah sebagai komunitas moral yang berbagi tanggung jawab untuk pendidikan karakter dan setia pada nilai dasar yang sama.

9. Adanya pembagian kepemimpinan moral dan dukungan luas dalam membangun inisiatif pendidikan karakter.

10. Memfungsikan keluarga dan anggota masyarakat sebagai mitra dalam usaha membangun karakter.

11. Mengevaluasi karakter sekolah, fungsi staf sekolah sebagai guruguru karakter.
Dan Aqib dan Sujak (2011: 11) menuliskan prinsip pendidikan karakter pada sebuah sekolah, bahwa pendidikan karakter harus didasarkan pada prinsip prinsip sebagai berikut:

1. Mempromosikan nilai-nilai dasar etika sebagai basis karakter.

2. Mengidentifikasi karakter secara komprehensif supaya mencakup pemikiran, perasaan, dan perilaku.

3. Menggunakan pendekatan yang tajam, proaktif dan efektif untuk membangun karakter.

4. Menciptakan komunitas sekolah yang memiliki kepedulian.

5. Memberi kesempatan kepada peserta didik untuk menunjukkan perilaku yang baik.

6. Memiliki cakupan terhadap kurikulum yang bermakna dan menantang yang menghargai semua peserta didik, membangun karakter mereka, dan membantu mereka untuk sukses.

7. Mengusahakan tumbuhnya motivasi diri pada para peserta didik.

8. Memfungsikan seluruh staf sekolah sebagai komunitas moral yang berbagi tanggung jawab untuk pendidikan karakter dan setia pada nilai dasar yang sama.

9. Adanya pembagian kepemimpinan moral dan dukungan luas dalam membangun inisiatif pendidikan karakter.

10. Memfungsikan keluarga dan anggota masyarakat sebagai mitra dalam usaha membangun karakter.

11. Mengevaluasi karakter sekolah, fungsi staf sekolah sebagai guruguru karakter, dan manifestasi karakter positif dalam kehidupan peserta didik. 
Berdasarkan pendapat dari banyak pakar pendidikan anak, Megawangi (2004:151) menyimpulkan ada dua faktor penentu terbentuknya karakter pada manusia, yaitu nature (faktor alami atau fitrah) dan nurture (sosialisasi dan pendidikan).

Megawangi sebagaimana yang dikutip oleh Q-Anees dan Hambali (2009: 107) menengarai perlunya penerapan $4 \mathrm{M}$ dalam pendidikan karakter, yaitu mengetahui, mencintai, menginginkan, dan mengerjakan (knowing the good, loving the good, desiring the good, and acting the good) kebaikan secara simultan dan berkesinambungan.

Menurut Koesoema (2007: 9) "secara historis pendidikan karakter merupakan misi utama para nabi". Pernyataan tersebut sejalan dengan hadiś yang menyatakan bahwa Muhammad sebagai Rasulullah sedari awal diutus untuk menyempurnakan akhlak (karakter). Sebagaimana sebuah hadiś dibawah ini:

"Sesungguhnya aku diutus ke muka bumi ini adalah untuk menyempurnakan akhlak yang mulia". (diriwayatkan oleh Imam al-Bukhari di dalam kitab al-Adab al-Mufrad)

Sebagaimana yang telah dijelaskan sebelumnya bahwa pendidikan karakter merupakan tugas yang diemban oleh para Nabi. Pendidikan karakter untuk mensucikan jiwa, mengajarkan kitab dan hikmah, sebagaimana bunyi QS. AlJumu'ah (62): 2.

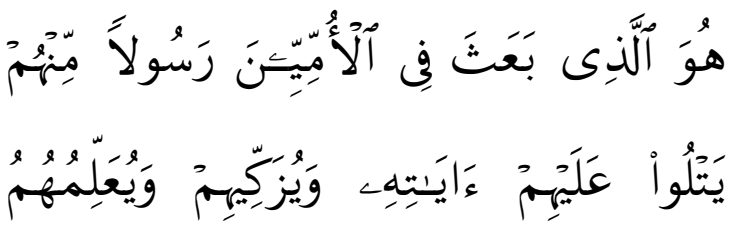

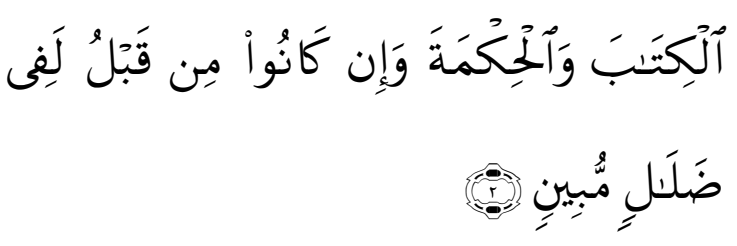

Artinya: "Dia-lah yang mengutus kepada kaum yang buta huruf seorang Rasul di antara mereka, yang membacakan ayat-ayat-Nya kepada mereka, mensucikan mereka dan mengajarkan mereka kitab dan Hikmah (As Sunnah). dan Sesungguhnya mereka sebelumnya benar-benar dalam kesesatan yang nyata"

\section{METODE}

Penelitian ini berjudul "Model Pendidikan Karakter di Islamic Full Day School (Studi Deskriptif pada SD Cendekia Leadership School). Berdasarkan judul tersebut, maka penelitian ini bersifat menggambarkan model pendidikan karakter di SD Cendekia Leadership School. Jadi penelitian ini menggunakan metode deskriptif. Sukmadinata (2005: 18) menjelaskan bahwa:

Penelitian deskriptif tidak melakukan manipulasi atau memberikan perlakuanperlakuan tertentu terhadap variabel atau merancang sesuatu yang diharapkan terjadi pada variabel, tetapi semua kegiatan, keadaan, kejadian, aspek, komponen atau variabel berjalan sebagaimana adanya.

Adapun pendekatan yang dipilih adalah pendekatan kualitatif, Bogdan dan Taylor sebagaimana dikutip oleh Moleong (2001: 3), mendefinisikan "pendekatan kualitatif sebagai prosedur penelitian yang menghasilkan data deskriptif berupa katakata tertulis atau lisan dari orang-orang dan perilaku yang dapat diamati". Tidak jauh berbeda dengan Moleong, 
Sukmadinata (2005: 18) memaparkan bahwa "penelitian deskriptif dengan pendekatan kualitatif merupakan penggambaran keadaan secara naratif kualitatif'.

Menurut Sugiyono (2008: 60) "peneliti kualitatif sebagai human instrument, berfungsi menetapkan fokus penelitian, memilih informan sebagai sumber data, melakukan pengumpulan data, menilai kualitas data, analisis data, menafsirkan data dan membuat kesimpulan atas semuanya".

Lokasi penelitian ini adalah tempat berlangsungnya penelitian yakni SD Cendekia Leadership School yang berada di jalan Ligar Taqwa No. 2 Komp. Bukit Ligar Bandung 40191. SD Cendekia Leadership School

Sumber data berupa data primer dan data sekunder, sumber data primer yang dipilih dalam penelitian ini yaitu: narasumber (informan), Peristiwa atau aktivitas tempat atau lokasi. Sedangkan sumber data sekunder yang menjadi rujukan peneliti dalam hal ini adalah semua dokumen SD Cendekia Leadership School baik berupa dokumen tertulis seperti peraturan sekolah, jadwal pelajaran, indikator kurikulum, unit plan, class letter, plan weekly, kalender akademik, akta sekolah, data jumlah siswa dan guru serta staf sekolah, struktur sekolah, data berkenaan dengan sarana dan prasarana yang dimiliki sekolah, dokumen yang berbentuk foto atau video dan data lain-lainnya.

Pengumpulan data dilakukan dengan observasi, wawancara, kajian dokumentasi dan triangulasi. Sedangkan Analisis data dalam penelitian kualitatif bersifat iteratif (berkelanjutan) dan dikembangkan sepanjang penelitian. Analisis data dilaksanakan mulai dari penetapan masalah, pengumpulan data, dan setelah data terkumpulkan. Analisis yang telah dilakukan secara umum dimulai sejak pengumpulan data, reduksi data, penyajian data, dan penarikan kesimpulan atau verifikasi.

\section{HASIL DAN PEMBAHASAN}

SD Cendekia Leadership School menerapkan perencanaan yang matang dalam pendidikan karakter, perencanaan tersebut dimulai dari pembuatan kalender akademik, penurunan indikator setiap ranah pada kurikulum dalam bentuk unit plan yang diberikan kepada setiap guru, kemudian setiap guru membuat plan week $y$ dan setiap guru kelas membuat class letter yang akan diberikan kepada para orang tua siswa dalam pertemuan parents meeting. Kemudian perencanaan berbagai kegiatan di luar intrakurikuler mengikuti perencanaan pada kalender akademik yang sudah di atur penanggung jawab masingmasing untuk setiap kegiatan atau events.

$$
\text { Kurikulum SD Cendekia }
$$

Leadership School terangkum dalam 7 Leadership Skills yakni understanding self, communicating, getting along with other, lerning to learn, making decision, managing, dan working with groups; dan 4H sistem yaitu; Hands, Head, Health dan Heart, keempat $\mathrm{H}$ sistem ini koheren dan saling berkaitan. Hands dibagi menjadi dua bagian yaitu Giving dan Working; Head dibagi dua yaitu Managing dan Thinking; Health dibagi menjadi dua yaitu living dan being; dan Heart yang dibagi menjadi dua juga yaitu Caring dan Relating. Sistem $4 \mathrm{H}$ tersebut adalah sebagai berikut. 


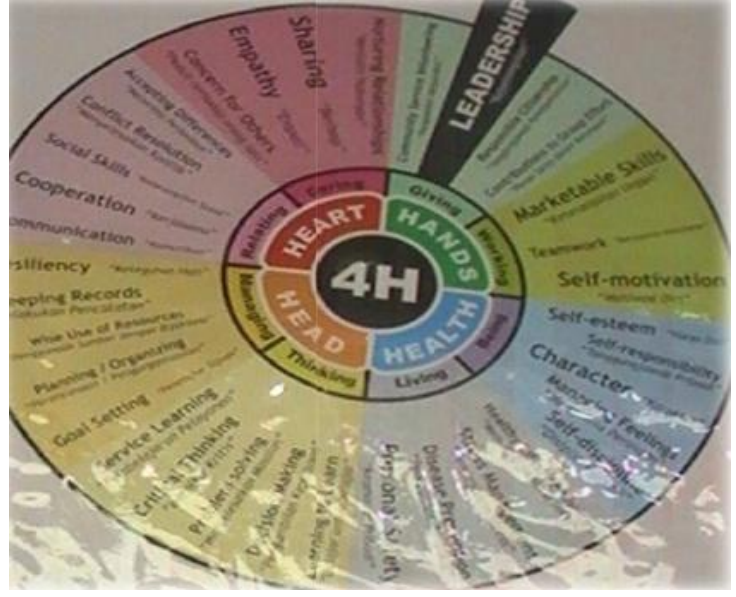

Gambar 2. Sistem 4H

Kekhasan dari SD Cendekia Leadership School adalah pelaksanaan pendidikan karakter menggunakan sistem pengorganisasian siswa. Siswa baru dan siswa lama dibagi dalam 4 kelompok kecil di setiap kelas yakni kelompok hands, head, health dan hearth. Setiap kelompok di kelas akan digabungkan dengan kelomp ok yang sama dikelas yang berbeda, misalnya kelompok hands kelas atau Grade 1, Grade 2, Grade 3, sampai dengan Grade 6 digabungkan menjadi kelompok hands dalam lingkup yang lebih besar, begitupun dengan kelompok head, health dan hearth.

Metode yang digunakan dalam pendidikan karakter adalah metode pengalaman langsung dan pembiasaan. Pada setiap kegiatan atau events dan pembelajaran di kelas, siswa di ajarkan untuk merasakan langsung baik secara visual, audio dan tindakan yang ia rasakan dan lakukan sendiri serta pembiasaan yakni penanaman karakter yang terusmenerus secara continue sampai siswa terbiasa.

Evaluasi dilakukan secara bertahap; yakni evaluasi harian, evaluasi setiap term, evaluasi setiap dua term. Evaluasi pada pendidikan karakter lebih banyak dilakukan dengan teknik non tes, yaitu teknik observasi, wawancara, kuesioner yang dibagikan kepada orang tua dan pemeriksaan dokumen-dokumen siswa. Alat evaluasi yang menjadi unggulan di SD Cendekia Leadership School adalah rubrik yang diberikan kepada orang tua siswa. Kemudian pihak sekolah bekerjasama dengan orang tua siswa dalam melakukan penilaian perkembangan karakter siswa di rumah.

Untuk mengatasi hambatanhambatan tersebut SD Cendekia Leadership School terus menerus melakukan perbaikan dan evaluasi serta mengadakan latihan untuk guru-guru dan membuat pertemuan rutin yang disebut dengan $b$-weekly. Pihak sekolah juga menyediakan fasilitas yang mendukung dan membantu para guru seperti psikolog, ruang ICT dan kemudahan melalui budgeting plan.

\section{KESIMPULAN}

Berdasarkan hasil penelitian dapat disimpulkan konstruk model pendidikan karakter di SD Cendekia Leadership School seperti pada gambar berikut. 


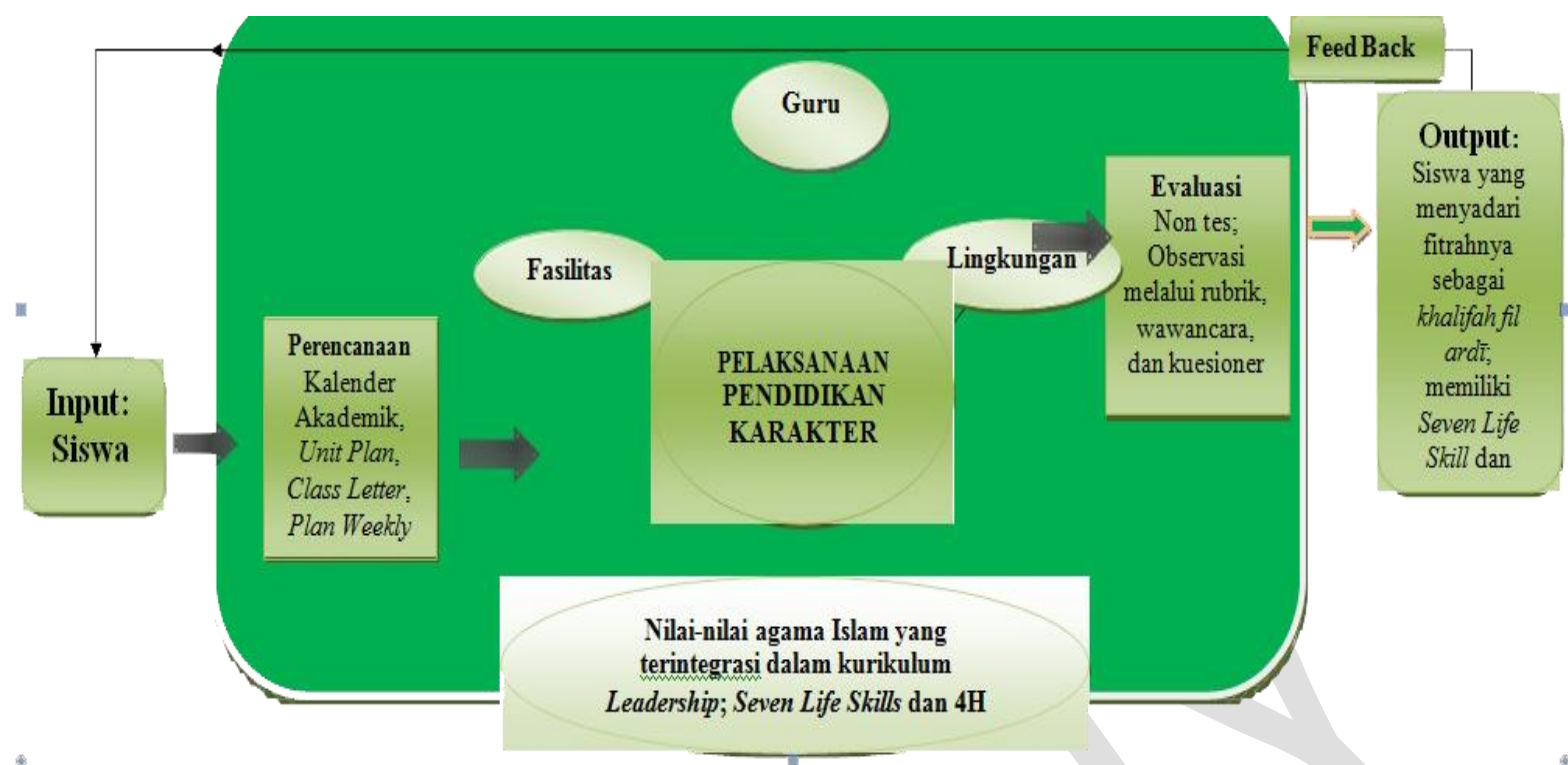

Gambar 3. Konstruk Model Pendidikan Karakter di SD Cendekia Leadership School

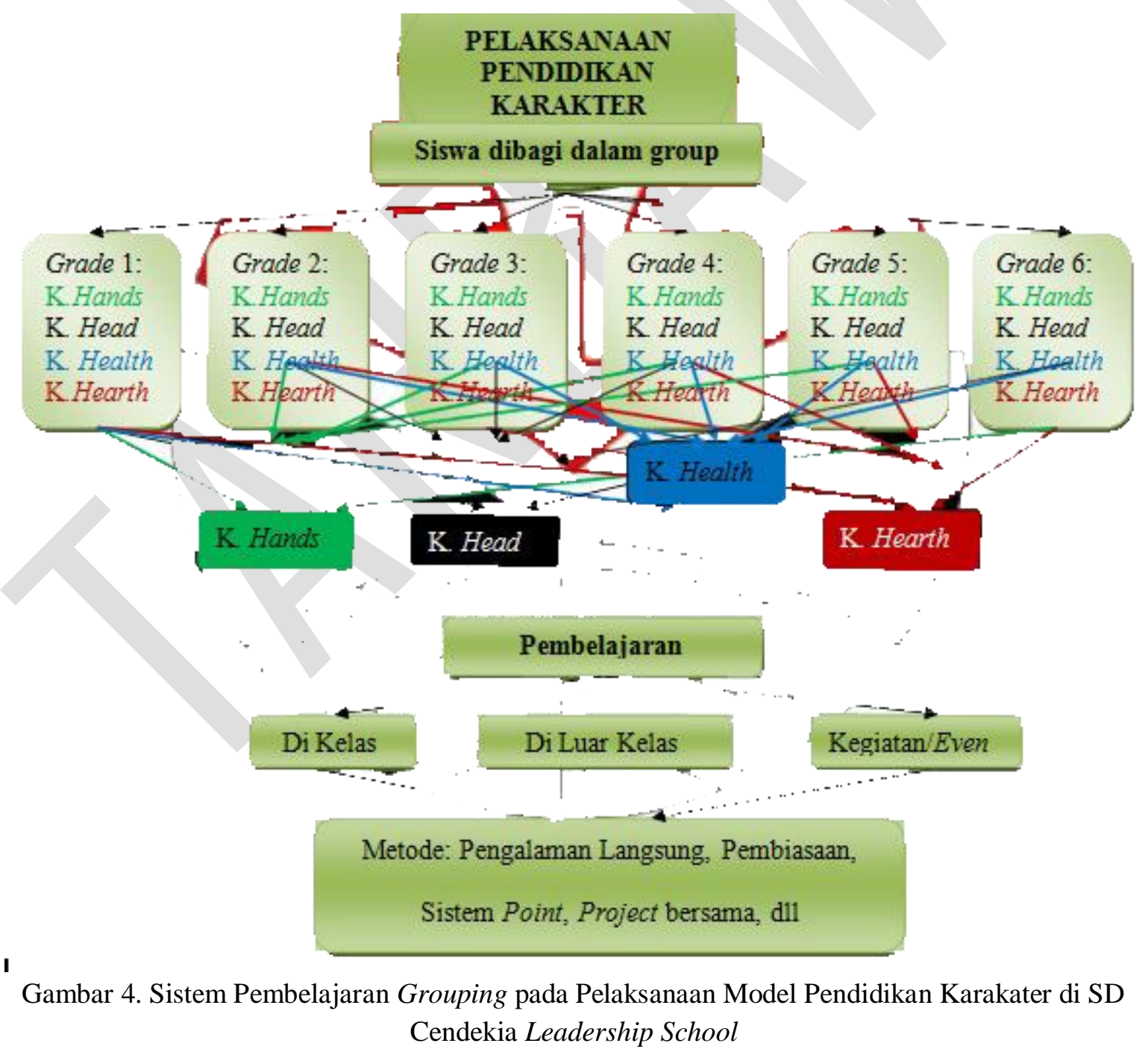

TARBAWY, Vol. 1, Nomor 2, (2014)| 140 


\section{REFERENSI}

---. (2007). Al-Qur'an Terjemah per Kata. (L. P. Al-Qur'an, Penerj.) Bandung: CV Haekal Media Centre Departemen Agama Republik Indonesia.

Asufudin, A. F. (2010). Menyucikan Jiwa, Membersihkan Qolbu. Dipetik September 7, 2011, dari http://ustadzfaiz.com/menyucikanjiwa-membersihkan-qalbu-1/

Bualim. (2008). Ringkasan Transkrip Audio Minhajul Anbiya $f i$ Tazkiyatun Nufus. Dipetik September 7, 2011, dari http://abunashir.blogspot.com/2008 /10/manhaj-para-nabi- dalamtazkiyatun-nufus_9750.html

Koesoema, D. (2009). Pendidikan Karakter di Zaman Keblinger. Jakarta: Grasindo.

Koesoema, D. (2007). Pendidikan Karakter Strategi Mendidik Anak di Zaman Global. Jakarta: Grasindo.

Megawangi, R. (2004). Pendidikan Karakter Solusi yang Tepat untuk Membangun Bangsa. Jakarta: BP Migas dan Star Energi.

Moleong, L. (2001). Metodologi Penelitian Pendidikan. Bandung: Rosda Karya.

Rasyidin. (2008). Landasan Pendidikan. Bandung: UPI Press.

Sismanto. (2008). Pesantren VS Full Day System. Dipetik September 7, 2011, dari http://buntetpesantren.org/index.ph p?option=com_content $\&$ view $=$ artic le

Sugiyono. (2008). Memahami Penelitian Kualitatif. Bandung: Alfabeta.

Sujak, Z. A. (2011). Panduan \& Aplikasi Pendidikan Karakter. Bandung: Yrama Widya.

Sukmadinata, N. S. (2002). Metode Penelitian Pendidikan. Bandung: Rosda Karya.

i

